Thorax (1962), 17, 251.

\title{
PULMONARY ALVEOLAR MICROLITHIASIS
}

\author{
BY \\ R. VISWANATHAN \\ From the Vallabhbhai Patel Chest Institute, University of Delhi, India
}

(RECEIVED FOR PUBliCATION JULY 29, 1961)

The object of this communication is to review the literature on pulmonary alveolar microlithiasis, to give a description of the disease on the basis of the information available, and to report on two new cases seen in siblings. As far as I am aware, no previous report of any case has been made from India.

\section{REVIEW OF THE LiteratuRE}

Pulmonary alveolar microlithiasis is the name given by Puhr (1933) to a condition characterized by multiple minute calcifications mostly affecting the alveoli, giving a typical radiographic picture, and having a tendency to appear in siblings. A comprehensive review of the disease has been given by Sosman, Dodd, Jones, and Pillmore (1957) with reports of 24 cases seen by them. They reviewed 22 previous case reports (Table I).

TABLE I

CASES REVIEWED BY SOSMAN, DODD, JONES, AND PILLMORE (1957)

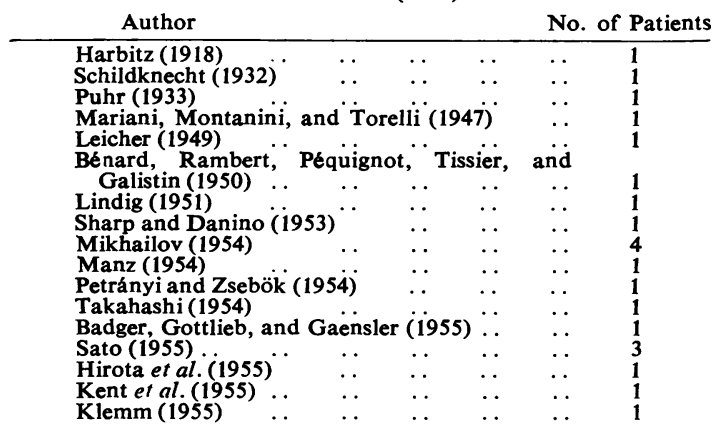

Since this exhaustive review, a few more cases of this disease have been reported from different parts of the world. Finkbiner, Decker, and Cooper (1957) have described the condition in a 31-year-old Negro in whom the diagnosis was established by means of pulmonary biopsy. Greenberg (1957) confirmed the diagnosis by lung biopsy in an apparently healthy schoolboy 11 vears old. Chinachoti and Tangchai (1957) discovered the disease in a man 40 years of age in Thailand. The patient was addicted to insufflation of snuff, which on analysis was found to contain $9.47 \%$ calcium besides other ingredients like tobacco. They have postulated that the lesion in their case might have resulted from a hyperimmune reaction to an inhaled irritant. Other patients have been reported from Norway (Laake, 1959), Columbia (Esguerra Gomez, Lichtemberger, Santamaría, Carvajal, Jiménez-Peñuela, Saabí, Rey Barrera, Orduz, and Correa-Henao, 1959), the Caribbean area (Cole, 1959), and the United Arab Republic (Abdel-Hakim, El-Mallah, Hashem, and Abdel-Halim, 1959). A full account of lung function tests indicated impairment of gas diffusion across the alveolar membrane, and uneven relative distribution of gas and blood in the lungs, which might lead to serious hypoxia on exertion (Thomson, 1959). More recently, Taxay, Montgomery, and Wildish (1960) have made further studies on Cole's case and have noted negative results by the therapeutic use of a chelating agent such as disodium versenate.

\section{SYMPTOMATOLOGY}

Most of the patients described in the medical literature have been discovered by accident during routine radiographic examinations. There is a variable latent period before symptoms appear, and most patients have been discovered after the thirtieth year. Cough is the common non-specific symptom for which the patient seeks medical advice. In the early stages there is very little expectoration, and a haemoptysis is rarely a symptom. Occasionally microliths might be coughed out, but microscopic examination is required to identify them. In the later stages the patient may develop progressive pulmonary insufficiency leading to heart failure.

Physical signs are few compared with the frightening appearance in the radiographs. This is one of the few conditions in which the paucity of symptoms and physical signs contrasts markedly 
with the gross changes revealed by radiography. These radiographic appearances can be considered quite characteristic: there is a fine sand-like mottling evenly distributed throughout both lungs, but there is much greater condensation at the bases. When the microliths are crowded together, large irregular dense shadows can be seen, which usually obscure the outlines of the heart and pulmonary blood vessels and the diaphragm.

Sosman et al. (1957) have demonstrated the progressive nature of the disease by serial studies in a number of cases, as shown by the increasing density of the radiographic shadowing.

\section{Age and Sex Incidence}

The sexes are affected almost equally, and there is no predominant incidence in any particular race as the disease has been reported from all parts of the world. Possibly the disease begins slowly in childhood, perhaps even from birth. Though most cases have been discovered after the age of 30 , nine patients under 20 have been reported. Manz (1954) discovered the condition in a girl of 12 and observed her progress for 25 years until she died.

\section{Pathology}

Necropsy reports suggest that the changes are limited to the lungs. The pleural surfaces are generally free though they appear grossly granular owing to the sand-like particles which can be seen and felt underneath the pleura. Occasionally dense fibrous adhesions can be seen. The lungs are usually hard and gritty and do not collapse on removal from the thorax. It has been reported that the harder portions of the lung had to be cut with a saw, and even the softer portions are cut with some difficulty. Emphysematous blebs are commonly seen at the apices and at the anterior margins. Histologically the concretions are considered to be similar in appearance to corpora amylacea, which are most commonly found in the prostate gland (Kent, Gilbert, and Meyer, 1955). Microliths vary in size from 0.02 to $0.3 \mathrm{~cm}$. and may have radial lines suggesting cracks crossing the circular or oval laminated rings. Kent et al. (1955) found doubly refractile lipids and a positive colloidal iron stain suggesting the presence of mucopolysaccharides. No cellular remnants can be identified in the microliths.

\section{Differential Diagnosis •}

In the absence of lung biopsy studies, the radiological picture may suggest conditions such as haemosiderosis, stannosis, histoplasmosis, meta- static carcinomatosis, pulmonary adenomatosis, chronic miliary tuberculosis, and miliary amyloidosis. In most cases, however, the characteristic evenly distributed micronodular radio-opaque shadows in the chest radiograph suggest the possibility of microlithiasis. When such extensive changes are associated with paucity of symptoms and signs the diagnosis becomes more certain. Lung biopsy can clinch the diagnosis.

\section{Aetiology}

The cause of this condition is unknown. Neither histological examination of the lungs nor chemical analysis of lung tissues and the microliths give any clue as to its possible aetiology. It has been suggested that the microliths may be produced by deposit of calcium phosphate and carbonate in an exudate or transudate in an otherwise apparently normal alveolus, though the real problem is to find out what causes this deposition. There is no evidence to show that the condition is due to any kind of infection, or the result of exposure to any kind of dust, or related to any collagen disease. The components of the microliths are probably derived from the alveolar capillary blood and are not a result of pathological changes in the tissue cells of the alveoli, since the alveolar walls themselves, particularly in the early stages, do not show any changes.

Considering the nature of the condition, no form of treatment will be useful: although chelating agents might be tried, they are of doubtful value.

\section{CASE Reports}

CASE 1.-An Indian man, aged 43 years, a homoeopath by profession, was referred as a possible case of histoplasmosis or sarcoidosis because of the extraordinary chest radiograph. Fifteen years previously he had worked for four years in a retail cement shop. On admission to the Institute he gave a history of slight cough with some mucoid expectoration for two months. He also complained of a burning sensation over the chest and shoulders. He had no exertional dyspnoea or any other subjective symptom. On examination he was fairly well nourished, had no anaemia and no clubbing of the fingers. The only abnormal physical signs in the lungs were occasional crepitations at the bases and his blood pressure was normal.

A radiograph of the lungs presented an extraordinary picture (Fig. 1). There were minute discrete sand-like shadows throughout both lungs, with coalescence of these shadows especially in the basal regions. The outlines of the heart and the pulmonary blood vessels could not be made out owing to the density of the shadows. Examination of the 

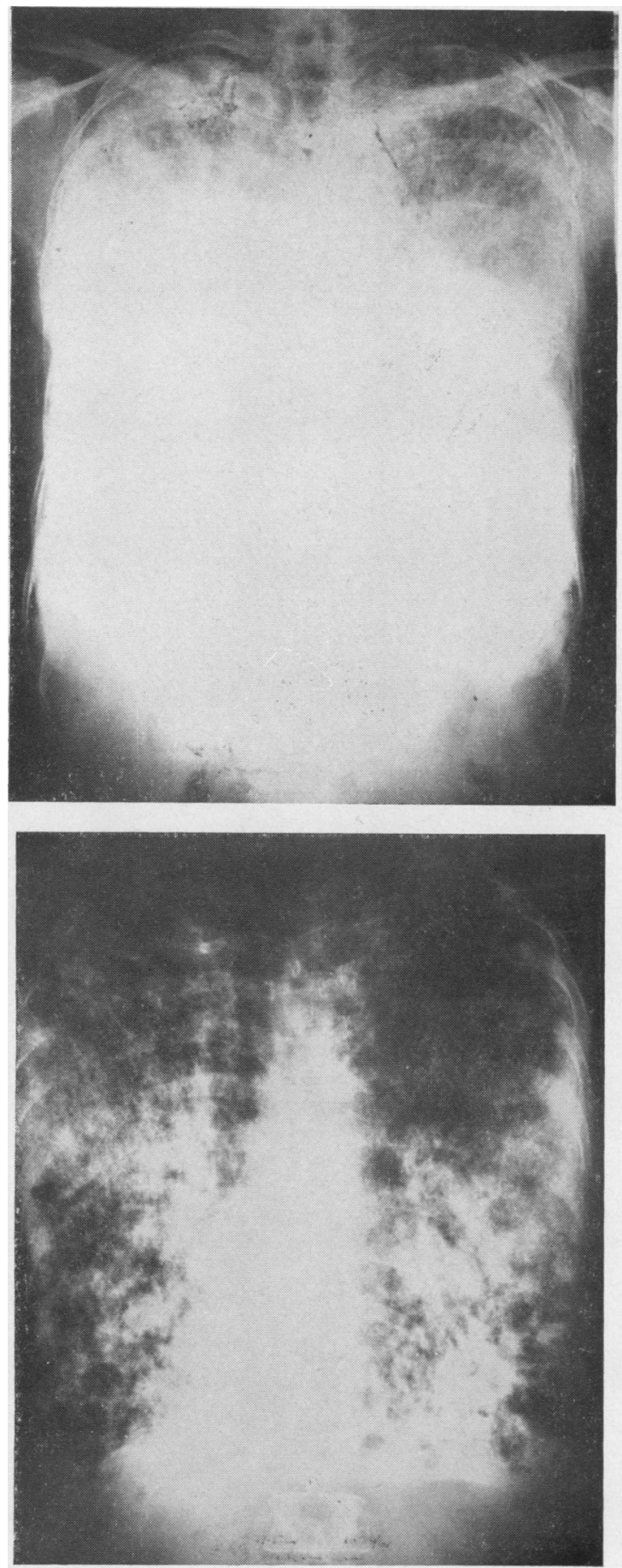

FIG. 1. Case 1. (above) Radiograph of the chest shows dense opacities in the mid and lower zones and fine sand-like shadows in the upper zones; the cardiac outiine is not visible: (below) a longer exposure using a PotterBuckey diaphragm. blood showed Hb 13.4 g./100 ml., R.B.C. $4.72 \times 10^{6} /$ c.mm., W.B.C. $4,900 /$ c.mm., with a normal differential count, and E.S.R. $40 \mathrm{~mm}$. for the first hour (Wintrobe). The urine was normal; the sputum was negative both by smear and by culture for acid-fast bacilli; no pathogenic bacteria were cultured, and mycological examination was negative. Pulmonary function tests gave the following results:

Lung Volumes (B.T.P.S.)

Vital capacity $\quad 1,870 \mathrm{ml}$.

Vital capacity (after bronchodilator) $2,040 \mathrm{ml}$.

Residual volume $\quad 2,278 \mathrm{ml}$.

Functional residual capacity $\quad 3,107 \mathrm{ml}$.

Total lung capacity

RV/TLC

$4,148 \mathrm{ml}$.

Ventilation (sitting)

Respiratory rate

Tidal volume

Minute volume

Respiratory dead space

Alveolar ventilation $55 \%$

\section{Distribution of Inspired Air}

Alveolar $\mathrm{N}_{2}$ at end of $7 \mathrm{~min}$. breathing of $99.2 \% \mathrm{O}_{2}$

$4.2 \%$

Mechanics of Breathing

Maximum mid-expiratory flow rate $781 . / \mathrm{min}$.

Maximum mid-expiratory flow rate after adrenaline

$78 \mathrm{l} . / \mathrm{min}$.

$15 / \mathrm{min}$

$333 \mathrm{ml}$.

$4,900 \mathrm{ml}$. $/ \mathrm{min}$.

$146 \mathrm{ml}$.

$3,116 \mathrm{ml} . / \mathrm{min}$

Forced expiratory volume (1 second) as $\%$ of vital capacity

$67 \%$

Forced expiratory volume (1 second) as \% of vital capacity after adrenaline

Maximum breathing capacity

Maximum breathing capacity after adrenaline

$521 . / \mathrm{min}$. $(60 \%$ normal $)$

Lung compliance Arterial oxygen tension $\left(\mathrm{PO}_{2}\right)$ $0.130 \mathrm{l} . / \mathrm{cm} . \mathrm{H}_{2} \mathrm{O}$

Arterial $\mathrm{CO}_{2}$ tension $\left(\mathrm{PCO}_{2}\right)$ $62 \mathrm{~mm} . \mathrm{Hg}$ $46.0 \quad 42.14$

Right heart catheterization revealed normal pressures throughout, and the cardiac output was 4.86 $1 . /$ min. by the Fick method.

Lung Biopsy.-Closed lung biopsy with a Silvermann needle was performed and a small piece of lung tissue was successfully removed without any untoward after-effects. The passage of the needle was difficult and there was a gritty feel throughout.

Microscopic examination of the biopsy material (Figs. 2, 3, and 4) showed that the alveolar walls were thin, containing fine capillaries and regularly disposed small round cells with compact nuclei. In between these an occasional large irregular cell with pale cytoplasm and prominent central nucleus could 


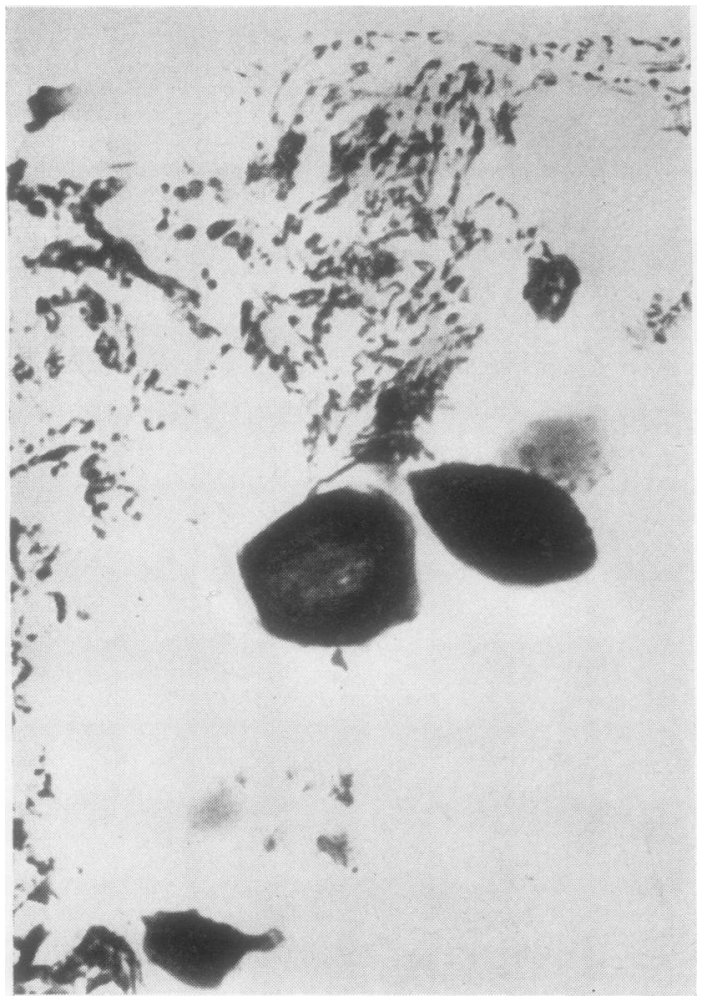

Fro. 2

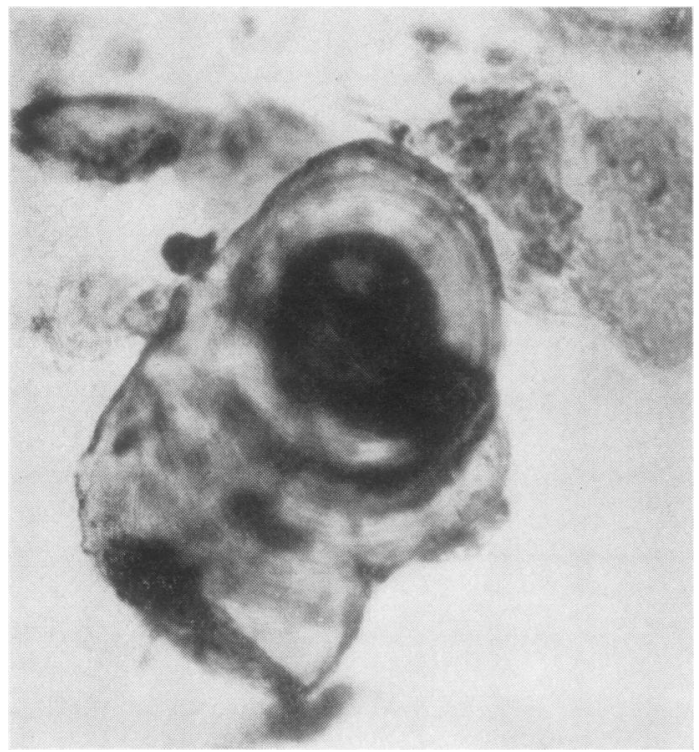

FIG. 4
FIG. 2. Lung tissue removed by needle biopsy shows $\dot{0}$ microliths. Alveolar walls show no sign of inflammation, $\times 120$.

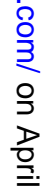

FIG. 3. A cluster of microliths, some with radial fissures, N $\times 120$. 
also be seen. In some places the alveolar septa were made up of fine fibrils and special staining showed them to consist of thickened elastic and reticulin fibres. There were also some fine collagenic fibres. The characteristic finding, however, was that of bluishviolet bodies of varying shape and size: the larger ones were rounded or oval, most were laminated, and many were fissured with radial cracks. With von Kossa stain the bodies appeared light brown or brownish black (calcium); they were also faintly positive for iron (Perls's reaction), and in the laminated bodies the circular markings were prominent, taking a deep bluish colour on iron stain. Some of these large bodies were closely related to the alveolar walls, jutting against them. The smaller bodies were markedly irregular, of varying shapes, refractile, and also positive for calcium and in places for iron. These bodies were highly refractile under polarized light. No microorganisms could be demonstrated by Gram's stain.

CASE 2.-An Indian woman, aged 51 years, the elder sister of Case 1, was brought to the Institute for examination with two other brothers with a view to finding out whether any of the siblings of Case 1 had similar disease. While chest radiographs of the brothers were normal, that of the sister showed a strikingly similar appearance to that of Case 1 . The patient was in apparent good health, but had had a slight cough for many years. There were no significant signs in the lungs, but the chest radiograph showed

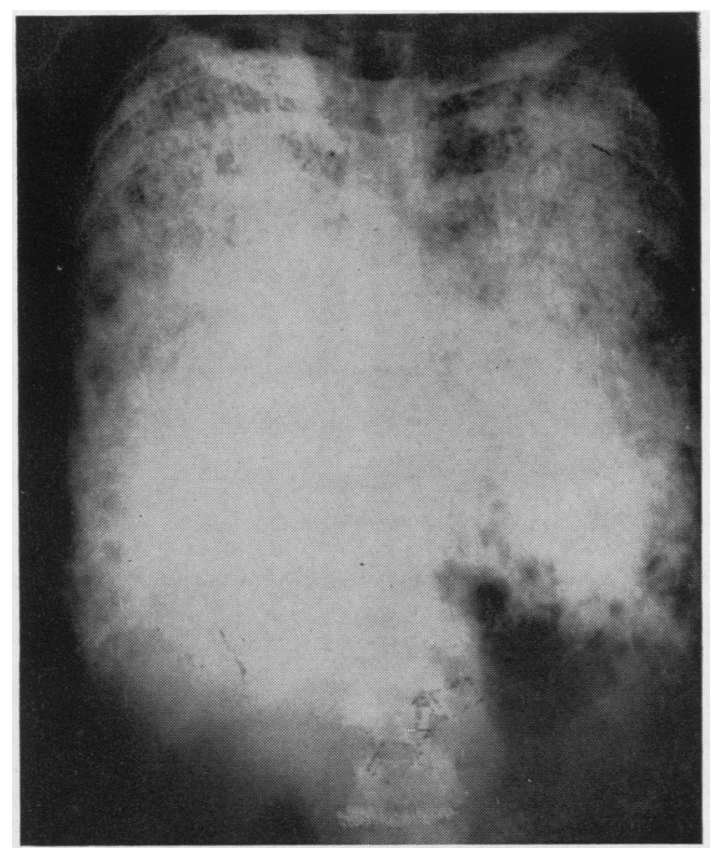

FIG. 5. Case 2. Radiograph of chest shows minute sandlike opacities. The cardiac outline is not visible. characteristic minute sand-like opacities distributed throughout both lungs with condensation here and there, particularly near the hila and in the basal region (Fig. 5). With great difficulty the patient was persuaded to give some blood for biochemical examination which showed serum calcium $11.16 \mathrm{mg}$./ $100 \mathrm{ml}$.; cholesterol $150 \mathrm{mg} . / 100 \mathrm{ml}$; blood urea nitrogen $5.8 \mathrm{mg}$. $/ 100 \mathrm{ml}$.; blood sugar $72 \mathrm{mg} . / 100 \mathrm{ml}$.; total proteins $8 \mathrm{~g} . / 100 \mathrm{ml}$.

A lung biopsy could not be done as she refused any further investigations.

\section{Discussion}

The characteristic radiographic findings of minute sand-like opacities in the lungs in the virtual absence of physical signs and significant symptoms are sufficient to make one suspect the possibility of pulmonary alveolar microlithiasis. Further confirmation of the diagnosis is obtained by the occurrence of the same condition in more than one sibling. In the first patient, the diagnosis has been confirmed by pulmonary biopsy. The characteristic chest radiograph, and the fact that her brother is suffering from the disease, is adequate evidence to justify the diagnosis of microlithiasis in the second patient as well.

Neither the biochemical examinations nor histological studies give any clue as to the aetiology of this condition.

Though the patient had no respiratory distress, even on a moderate degree of prolonged physical activity, pulmonary function tests show a restrictive type of pulmonary insufficiency as is evident from reduced lung volumes, proportionate reduction of maximum breathing capacity, and diminished compliance. An increase in the $\mathrm{RV} / \mathrm{TLC}$ ratio and a decrease in the maximum mid-expiratory flow rate and in the one-second forced expiratory volume are suggestive of a moderate degree of obstructive emphysema. Further evidence is provided by the uneven distribution of the inspired air, as shown by the low nitrogen elimination rate. There is a slight reduction in the oxygen tension of arterial blood at rest, and a greater reduction after exercise. It is possible that this might have resulted from the perfusion of under-ventilated alveoli or from a diffusion difficulty. Thomson (1959) found in his case a reduced uneven distribution of pulmonary blood flow, reduced lung compliance, uneven distribution of inspired gas, reduced maximum breathing capacity, and reduced vital and total lung capacities. Similar ventilatory defects have been previously reported by Finkbiner et al. (1957) and by Sosman et al. (1957). The impairment of 
gas diffusion observed by Thomson in his case and the slight desaturation of blood observed in the present case can be accounted for by the fact that the microliths occupy the whole of the alveolar spaces. In all probability there is no alveolar-capillary block, as there are very few changes in the alveolar walls. The increase in gamma globulin and raised sedimentation rate are suggestive of collagenosis. There is, however, no other evidence to suggest the possibility of a collagen disorder to account for the formation of microliths in the alveoli.

\section{SUMMARY}

The available literature on pulmonary alveolar microlithiasis has been briefly reviewed, and a short description of the disease is given. Cases seen for the first time in India are reported: they are in siblings.

Diagnosis in the first patient was confirmed by closed pulmonary biopsy. Evidence is given for making a diagnosis of microlithiasis in the second patient as well.

My thanks are due to my colleagues Drs. I. M. Gupta, N. P. Gupta, S. K. Jain, T. A. V. Subramaniam, and S. C. Charravarti for their assistance in these investigations.

\section{REFERENCES}

Abdel-Hakim, M., El-Mallah, S., Hashem, M., and Abdel-Halim, S. (1959). Thorax, 14, 263.

Badger, T. L., Gottlieb, L., and Gaensler, E. A. (1955). New Engl. J. Med., 253, 709.

Bénard, H., Rambert, P., Péquignot, H., Tissier, and Galistin, P. (1950).' Bull. Soc. méd. Hôp. Paris, 66, 482.

Chinachoti, N., and Tangchai, P. (1957). Dis. Chest, 32, 687.

Cole, W. R. (1959). J. Fac. Radiol. (Lond.), $10,54$.

Esguerra Gomez, G., Lichtemberger, E., Santamaría, A., Carvajal, L., Jiménez-Peñuela, B., Saaibí, E., Rey Barrera, A., Orduz C., E., and Correa-Henao, A. (1959). Radiology, 72, 550.

Finkbiner, R. B., Decker, J. P., and Cooper, D. A. (1957). Amer. Rev. Tuberc., 75, 122.

Greenberg, M. J. (1957). Thorax, 12, 171.

Harbitz, F. (1918). Arch. intern. Med., 21, 139.

Hirota, S., et al. (1955). Nippon Rinsho Kekkaku, 14, 834.

Kent, G., Gilbert, E. S., and Meyer, H. H. (1955). A.M.A., Arch. Path., 60, 556.

Klemm, F. W. (1955). Fortschr. Röntgenstr., 83, 686.

Laake, H. (1959). Acta tuberc. scand., 36, 249.

Leicher, F. (1949). Zbl. allg. Path. Anat., 85, 49.

Lindig, W. (1951). Fortschr. Röntgenstr., 75, 678.

Manz, A. (1954). Beitr. Klin. Tuberk., 111, 598.

Mariani, B., Montanini, N., and Torelli, G. (1947). Ann. Ist. Forlanini, 10, 179.

Mikhailov, V. (1954). Klin. Med. (Mosk.), 32, 31.

Petrányi, G., and Zsebök, Z. (1954). Radiol.clin. (Basel), 23, 202.

Puhr, L. (1933). Virchows Arch. path. Anat., 290, 156.

Sato, K. (1955). Sci. Rep. Res. Inst. Tohoku Univ., Ser. C, 6, 391.

Schildknecht, O. (1932). Virchows Arch. path. Anat., 285, 466.

Sharp, M. E., and Danino, E. A. (1953). J. Path. Bact., 65, 389.

Sosman, M. C., Dodd, G. D., Jones, W. Duane, and Pillmore, G. U (1957). Amer. J. Roentgenol., 77, 947.

Takahashi, Y. (1954). Nippon Rinsho, 12, 89.

Taxay, E. P., Montgomery, R. D., and Wildish, D. M. (1960). Amer. J. clin. Path., 34, 532 .

Thomson, W. B. (1959). Thorax, 14, 76. 